\title{
Low-grade appendiceal mucinous neoplasm -rare neoplasm: a case report
}

\begin{abstract}
We present the case of a 39 year old patient admitted to local area Hospital with acute abdominal pain mimicking an intraperitoneal septic condition caused possibly by acute appendicitis. CT and ultrasound scan showed a mass situated in the right iliac fossa. The patient was submitted to laparotomy and right Hemicolectomy. The operative findings were suggestive of an appendiceal mucocele. The histology report revealed a low-grade appendiceal mucinous neoplasm. The patient had no clinical, biochemical or visual signs of disease recurrence 2 months postoperatively.
\end{abstract}

Keywords: low-grade appendiceal tumor, acute abdomen
Volume 9 Issue 2 - 2018

\author{
Asit kumar mohanty, Gitika anand, Jaroslav \\ nemec, Abdulsalam alnajjar, Jasem albarrak \\ 'Department of Medical Oncology, Kuwait \\ ${ }^{2}$ Department of Pathology, Sabah hospital, Kuwait
}

Correspondence: Asit Kumar Mohanty, Senior Registrar, Department of Medical Oncology, KCCC, Kuwait, Email asitmohanty4u@Gmail.com

Received: December 04, 2017 | Published: March 26, 2018

\section{Introduction}

Tumors of the appendix are rare clinical entities occurring in less than $2 \%$ of all appendectomies. ${ }^{1}$ Appendiceal tumors that can be confidently placed in the low-grade group and are confined to the appendix are considered clinically benign. ${ }^{2}$ Frequently, these tumors are discovered incidentally either during a survey or at the time of surgery for other causes. ${ }^{3}$ Their clinical significance lies with the possibility of rupture of the appendix and spillage of mucin into the peritoneal cavity resulting in pesudomyxoma peritonea, a complication that is followed by worse outcome than non-ruptured cases. ${ }^{4}$ Thus, preoperative recognition of an appendiceal mucocele is important because a possible rupture of the organ is imminent before or even during surgery. Of those patients proved to have a mucocele during surgery, approximately 40\% (13/37) have been diagnosed preoperatively as acute appendicitis on clinical grounds alone. ${ }^{5}$

We report a low-grade appendiceal mucinous neoplasm referred to our department for further management. He presented to local area hospital with a clinical picture of an acute abdomen with a palpable mass which was managed as a surgical emergency.

\section{Case presentation}

A 39-year-old male patient presented to local area Hospital with acute severe right iliac fossa pain of $24 \mathrm{~h}$ duration and a fever of $37.5^{\circ} \mathrm{C}$. The pain was continuous and confined to the lower abdomen with no exacerbations or remissions. There was no radiation of pain; on admission it was located mainly in the hypogastrium and right iliac fossa. No history of aggravating or relieving factors was elicited. The patient had no anorexia, nausea, and vomiting or weight loss. On examination the general appearance of the patient was unaffected. The abdomen was not distended and no guarding or spasm was elicited. There was rebound tenderness and a tender mass was felt in the right iliac fossa on palpation. In the hospital where he was first admitted, the patient had routine blood tests done and plain X-rays of the abdomen (erect and supine) as well as a chest X-ray. At that time he was also submitted to a CT scan of the abdomen (Fig-1). The findings from the CT scan revealed a cystic mass of about $8 \mathrm{~cm}$ maximum diameter, located to the right, superiorly to the bladder. An ultrasound scan was requested after he was admitted to our hospital.

\section{Hematology and biochemical tests}

The hematology tests showed Hct 35.4g/dl, WBC 11.6/ $/$ l (71.4\% neutrophils), Hgb 14.2g/dl, PLT 235,000/mm3. The biochemistry results showed blood sugar $126 \mathrm{mg} / \mathrm{dl}(75-115)$, urea $39 \mathrm{mg} / \mathrm{dl}(10-$ 50 ), creatinine $0.80 \mathrm{mg} / \mathrm{dl}(0.66-1.09)$, total proteins $7.6 \mathrm{~g} / \mathrm{dl}(6.4-8.3)$, (albumin $4.40 \mathrm{~g} / \mathrm{dl}[3.5-5.2]$ ), total bilirubin $0.81 \mathrm{mg} / \mathrm{dl}$ (up to 1.1 ), (direct bilirubin $0.19 \mathrm{mg} / \mathrm{dl}$ [0.01-0.4]), SGOT(AST) $18 \mathrm{IU} / 1$ (1035), SGPT(ALT) 24 IU/1 (10-35), $\gamma$ GT 12 U/1 (9-35), ALP 44IU/1 (35-104), LDH 224IU/1 (135-225), serum amylase 49U/1 (0-90), potassium $4.1 \mathrm{mmol} / 1$ (3.5-5.3), sodium $139 \mathrm{mmol} / 1$ (135-153), and calcium $10.0 \mathrm{mg} / \mathrm{dl}$ (8.4-10.4). The free peritoneal fluid that was sampled during surgery was exudates (Figure 1).

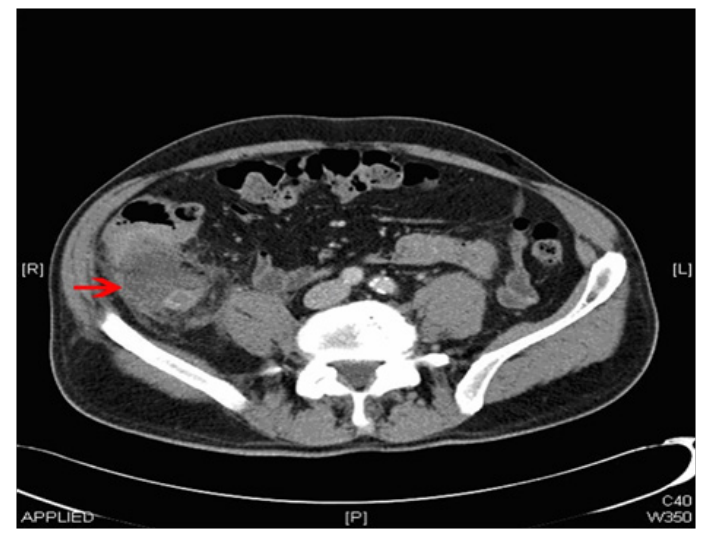

Figure I CT scan of the abdomen 


\section{Imaging}

The chest X-ray was normal and the plain abdominal films showed dilated intestinal loop(s) in the right iliac fossa. The findings from the CT scan revealed a cystic mass of about $8 \mathrm{~cm}$ maximum diameter, located to the right, superiorly to the bladder, containing contrast material, with simultaneous 'inflammatory' infiltration (misty appearance) of the surrounding fibro-fatty tissue.

\section{Surgery}

The patient underwent a laparotomy through a midline incision on 3rd august 2017. A mass representing a dilated caecum with a tense and smooth wall was identified in the right iliac fossa. A normal or acutely inflamed appendix was not recognized. Based on the experience of the surgeons, a mucocele of the appendix was suspected. The peritoneal cavity contained a small amount of inflammatory exudates. Fluid samples were taken for bacteriological examination and cytology. Following full examination of the peritoneal cavity, a standard right Hemicolectomy was performed. The dissection of the mass off the surrounding tissue was performed fairly easily. The cystic mass remained intact during the procedure, with no leakage into the peritoneal cavity. The patient had an uneventful postoperative recovery.

\section{Postoperative investigation}

\section{Pathology}

Macroscopic examination of the specimen revealed a gross dilatation of the caecal area measuring $8 \times 7 \times 7 \mathrm{~cm}$ with abundant mucin in the lumen. Base of appendix was involved by tumor. HP type low grade mucinous appendiceal neoplasm, grade I, no microscopic tumor extension, all margins were free, no LVI, no PNI, pTis,NxMx.The peritoneal fluid was also free of any septic flora (Figure 2).

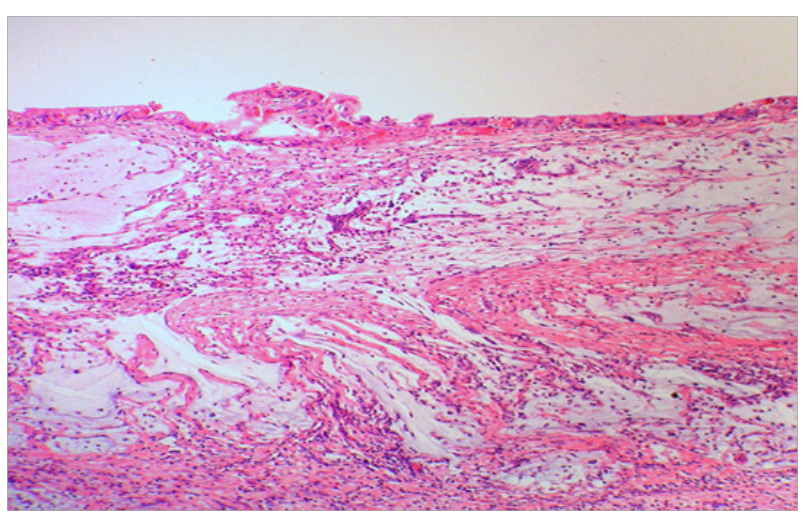

Figure 2 Macroscopic examination of the specimen

\section{Discussion}

Low-grade appendiceal mucinous neoplasm (LAMN) is a rare tumor of the appendix associated with cystic dilatation, to which the more general term of mucocele has been applied. Mucocele of the appendix denotes an obstructive dilatation of the appendiceal lumen due to abnormal accumulation of mucus, which may be caused by a retention cyst, mucosal hyperplasia, cystadenoma and cystadenocarcinoma. ${ }^{6,7}$ Mucocele of the appendix is more frequent in women and is usually observed in patients older than 50 years. The most common presenting symptom associated with LAMN has been abdominal pain; other symptoms such as bloody stool, intussusception have also been reported. ${ }^{8}$ Without specific symptoms, image studies are usually needed for differential diagnosis. By ultrasound, cystic masses with varying internal echogenicity and a layered wall with calcification may be seen. The typical findings by computed tomography are well-encapsulated cystic masses with low attenuation. However, if the mucocele ruptures, it may be misdiagnosed as ruptured appendicitis or diverticulitis. Colonoscopy is usually non diagnostic, as mucosal biopsies will often be normal. , $7,9^{7}$ LAMN generally grow slowly, and tend to produce the clinical picture of low-grade pesudomyxoma peritonea in which spread beyond the peritoneum or nodal metastasis is unusual. They tend to involve the appendix in a circumferential fashion with atrophy of the underlying lymphoid tissue. ${ }^{8}$ Because LAMN can proliferate outside the appendix in a malignant way, producing pesudomyxoma peritonea and even distant metastasis. ${ }^{10,11}$ It is inappropriate to regard LAMN as "one kind of adenoma". The term "mucinous cystadenocarcinoma" has been used for well-differentiated mucinous tumor with cystic structures; however, such a diagnosis should be avoided because this neoplasm does not constitute a separate disease entity. ${ }^{12}$ The $4^{\text {th }}$ edition of World Health Organization (WHO) classification asserted "low-grade appendiceal mucinous neoplasm" the appropriate name. The morbidity/mortality associated with LAMN stems from rupture and intraperitoneal spread of mucin-producing epithelium, which may cause pesudomyxoma peritonea. As a result, gentle tissue handling during operation cannot be overemphasized. ${ }^{13}$ Since there are no evidence in regard to lymphatic or hematogenous spreading of LAMN, if the mass confines in the appendix body without local invasion or cecal involvement, simple appendectomy and mesoappendix excision is considered sufficient treatment. ${ }^{14}$ Successful removal of appendiceal mucocele laparoscopically has been reported..$^{15,16}$

Our patient presented to the hospital with the warning sign of acute abdominal pain and was submitted early to laparotomy and right Hemicolectomy, a procedure that offered him better chances of survival; otherwise, if a rupture of the appendiceal lesion had occurred, the life-threatening complication of pesudomyxoma peritonea would definitely have ensued. Our patient's main clinical and laboratory findings which were free of confounding homeostatic complications emphasize the potential heterogeneity of this disease entity ${ }^{2}$ and suggest that the overall presentation and outcome of this case is likely to be characteristic, defining also a new phenotypic subset of this particular disease entity. The patient was referred to us medical oncology for further management But as it was a clear surgery and there is no mucin spillage during surgery so case was discussed in our GI MDT and The patient has been placed on 3 monthly follow-up examinations, and he is well after 3 months postoperatively.

\section{Conclusion}

Low-grade appendiceal mucinous neoplasm is more frequent in elderly patients and may cause acute abdomen. USG, CT and sometimes colonoscopy are helpful in diagnosis. However, actual diagnosis is usually made intraoperative or during histopathologic examination of the excised specimen. Appendectomy with removal of the mesoappendix or right Hemicolectomy is the treatment of choice, depending on the degree of tumor invasion. It may coexist with other neoplasms. Thorough examination of the abdominal and pelvic cavity during surgery is warranted. Follow-up CT, USG or colonoscopy are also recommended. 


\section{Acknowledgement}

None.

\section{Conflict of interest}

Authors declare there is no conflict of interest in publishing the article.

\section{References}

1. Marudanayagam R, Williams GT, Rees BI. Review of the pathological results of 2,660 appendicectomy specimens. J Gastroenterol. 2006;41:745749

2. Misdraji J, Yantiss RK, Graeme-Cook FM, et al. Appendiceal mucinous neoplasms: a clinicopathologic analysis of 107 cases. Am J Surg Pathol. 2003;27:1089-1103.

3. Bradley RF, Stewart JH, Russell GB, et al. Pseudomyxoma peritonei of appendiceal origin: a clinicopathologic analysis of 101 patients uniformly treated at a single institution, with literature review. Am J Surg Pathol. 2006;30:551-559.

4. Lee J, Gardiner KR, Wilson BG. Incidental mucinous cystadenocarcinoma of the appendix. Postgraduate Med J. 1996;72:55-56.

5. Ruiz-Tovar J, Teruel DG, Castineiras VM, et al. Mucocele of the appendix. World J Surg. 2007;31:542-548.

6. Kim SH, Lim HK, Lee WJ, et al. Mucocele of the appendix: ultrasonographic and CT findings. Abdom Imaging. 1998;23:292-6.

7. Madwed D, Mindelzun R, Jeffrey RB. Mucocele of the appendix: imaging findings. AJR Am J Roentgenol. 1992;159:69-72.

8. Misdraji J, Yantiss RK. Appendiceal mucinous neoplasms a clinicopathologic analysis of 107 cases. The American Journal of Surgical Pathology. 27:1089-103.

9. Kahn M, Friedman IH. Mucocele of the appendix: diagnosis and surgical management. Dis Colon Rectum. 1979;22:267-9.

10. Carr NJ, Sobin LH. Unusual tumors of the appendix and pseudomyxoma peritonei. Semin Diagn Pathol. 1996;13: 314-25.

11. Seidman JD, Elsayed AM, Sobin LH, et al. Association of mucinous tumors of the ovary and appendix: a clinicopathologic study of 25 cases. Am J Surg Pathol. 1993;17: 22-34.

12. Ronnett BM, Yan H, Kurman RJ, et al. Patients with pseudomyxoma peritonei associated with disseminated peritoneal adenomucinosis have a significantly more favorable prognosis than patients with peritoneal mucinous carcinomatosis. Cancer. 2001;92:85-91.

13. Kahn M, Friedman IH. Mucocele of the appendix: diagnosis and surgical management. Dis Colon Rectum. 1979;22:267-9.

14. Shayani V. Mucinous cystadenoma of the cecum missed at laparoscopic appendectomy. Surg Endosc. 1999;13:1236-7.

15. Lau H, Yuen WK, Loong F, et al. Laparoscopic resection of an appendiceal mucocele. Surg Laparosc Endosc Percutan Tech. 2002;12:367-70.

16. Navarra G, Asopa V, Basaglia E, et al. Mucous cystadenoma of the appendix: is it safe to remove it by a laparoscopic approach? Surg Endosc. 2003;17:833-4. 